\title{
Long-term effects of risperidone versus haloperidol on verbal memory, attention, and symptomatology in schizophrenia
}

\author{
SOPHIE RÉMILLARD, ${ }^{1}$ EMMANUELLE POURCHER, ${ }^{2,3}$ AND HENRI COHEN ${ }^{1-3}$ \\ ${ }^{1}$ Cognitive Science Institute, Université du Québec à Montréal, Montreal, Canada \\ ${ }^{2}$ Quebec Memory and Motor Skills Disorders Research Center, Clinique Sainte-Anne, Québec City, Canada \\ ${ }^{3}$ Psychology and Cognitive Neuroscience Laboratory, Université Paris Descartes - CNRS, France
}

(Received January 4, 2007; Final Revision July 9, 2007; AcCePted July 10, 2007)

\begin{abstract}
There is evidence in the literature that cognitive functions in schizophrenia (SC) may be improved by atypical neuroleptics (NLPs) in contrast to typical medication, but there is still controversy regarding this apparent superiority of atypical drugs. In this study, we assessed the differential effects of risperidone and haloperidol on verbal memory, attention, and psychiatric symptoms in SC. The performance of $28 \mathrm{SC}$ participants, randomly assigned to risperidone (2-6 mg/day) or haloperidol (2-40 mg/day), was compared with that of healthy controls. The California Verbal Learning Test (CVLT), the d2 Cancellation Test, and the Positive and Negative Symptoms Scale were administered at baseline and 3, 6, and 12 months. Relative to controls, all SC participants showed markedly impaired verbal memory and processing speed at each assessment period. There was no differential effect between the two NLPs on CVLT and d2 performance. However, risperidone was more effective than haloperidol in reducing psychiatric symptoms. Improvement in symptom severity was not associated with improvement in neurocognitive performance on these specific tests. Neither conventional nor atypical neuroleptic medications improved neurocognitive functioning over a 12-month follow-up, suggesting that psychopathological improvement under risperidone is independent of cognitive function. (JINS, 2008, 14, 110-118.)
\end{abstract}

Keywords: Cognitive impairment, Neuroleptic, Longitudinal assessment, Neuropsychological deficits, Speed processing, Recall

\section{INTRODUCTION}

Neurocognitive impairments of verbal learning and memory are among the most severe symptoms of schizophrenia (SC; Aleman et al., 1999; Hill et al., 2004; Paulsen et al., 1995) and have a major impact on patients' everyday activities (Green, 1996). Structural and functional neuroimaging studies in SC have shown evidence of a dysfunction affecting the hippocampus, a brain region that underlies specific memory and learning functions such as conscious recollection of deeply encoded items (Fukuzako et al., 1995; Heckers et al., 1998; Weiss et al., 2004). The hippocampus plays a determining role in the consolidation of short-term memory stores in long-term memory. Dysfunction of the left

Correspondence and reprint request to: Henri Cohen, Psychology and Cognitive Neuroscience Laboratory, Université Paris Descartes-CNRS, 71 Ave. Edouard-Vaillant, Boulogne-Billancourt 92774, France. E-mail: henri.cohen@univ-paris5.fr frontal cortex has also been associated with memory encoding deficits (Fletcher et al., 1998; Shallice et al., 1994; Tulving et al., 1994). Specifically, performance on verbal learning tasks, such as the California Verbal Learning Test (CVLT; Delis et al., 1987) has been associated with brain activity in both the hippocampus and the prefrontal cortex of healthy participants (Johnson et al., 2001). Because attention processes have been associated with activity in the prefrontal brain area (Toichi et al., 2004; Vendrell et al., 1995), questions remain as to whether memory impairments may be caused by other cognitive difficulties such as attentional dysfunction. Thus, some authors have suggested that problems with sustained and focused attention underlie the poor memory performance of patients with SC (Holthausen et al., 2003; Nuechterlein \& Dawson, 1984).

Since the introduction of risperidone, an atypical neuroleptic (NLP) treatment, there has been evidence of higher cognitive efficiency in SC patients treated with this NLP 
(Harvey et al., 2003). In contrast to typical drugs, neurocognitive improvements have been observed with risperidone treatment in the domain of verbal memory (Bilder et al., 2002; Kern et al., 1999) and attention (Harvey et al., 2000; Stip \& Lussier, 1996). However, this is not always the case, as other studies have shown no difference between the effects of typical NLP and risperidone treatments on attention (Liu et al., 2000) and verbal learning and memory (Cuesta et al., 2001; Green et al., 2002; Purdon et al., 2000; Stip \& Lussier, 1996). These divergent results may be due to differing methodological approaches. In the majority of studies, there is no healthy comparison group (Bilder et al., 2002; Cuesta et al., 2001; Green et al., 2002; Harvey et al., 2003; Kern et al., 1999; Liu et al., 2000; Purdon et al., 2000; Stip \& Lussier, 1996); other studies are conducted at a specific point in time (or over a rather short period; Bilder et al., 2002; Harvey et al., 2000, 2003; Hong et al., 2002; Kern et al., 1999; Liu et al., 2000); and some considered the effects of a single treatment only (Stip \& Lussier, 1996) or did not use a conventional NLP as a comparison group (Harvey et al., 2003).

Different hypotheses regarding the cognitive enhancement seen with atypical NLP treatment have been proposed. Selectivity for dopaminergic modulation in the mesolimbic and prefrontal cortex, avoiding the $\mathrm{D}_{2}$ blockade in the associative and sensorimotor parts of the basal ganglia, is one suggestion; this would result in a reduced need for anticholinergic medication and a direct benefit on verbal memory abilities (Kern et al., 1999). Mori et al. (2002) observed a significant improvement in the immediate memory and verbal working memory of SC patients after anticholinergic treatment had been withdrawn for 2 weeks. Other authors have also reported that higher anticholinergic drug dosages are associated with deficits in free recall (Paulsen et al., 1995) and reduced semantic clustering (Strauss et al., 1990).

Another explanation derives from the mixed $5 \mathrm{HT}_{2} / \mathrm{D}_{2}$ receptor blockade property common to atypical NLPs, which has been shown experimentally to increase the release of dopamine in the prefrontal cortex, with a direct impact on attention and working memory (Meltzer \& McGurk, 1999). A third explanation of verbal memory enhancement with atypical NLPs is directly linked to optimal control over clinical symptoms, especially negative symptoms (Hong et al., 2002). Atypical drugs have been found to improve psychopathological symptoms over conventional NLP drugs. Risperidone was found to be more effective than haloperidol in reducing the positive symptoms of SC, but also improved negative symptoms of individuals more than conventional NLP medications (Peuskens, 1995; Rabinowitz $\&$ Davidson, 2001; Yen et al., 2004). Thus, the aim of many studies was to investigate the relationship between neurocognitive dysfunction and the severity of psychopathology in individuals with SC. Bozikas et al. (2004) found the severity of negative symptoms to be mainly correlated with deficits of executive functions, semantic memory, and verbal memory. Aleman et al. (1999) also observed an associ- ation between poor memory performance and negative symptoms in SC patients. However, there is still some controversy regarding the association between improvements in cognitive symptoms and in psychiatric symptoms, as several studies have failed to reveal any relationship between either negative or positive symptoms and cognitive performance, including attention and verbal memory (Epstein et al., 1996; Hughes et al., 2003; Liu et al., 2000; Rémillard et al., 2005).

\section{Aims of the study}

From this perspective, the aim of the present study was to determine the long-term effects of two classes of NLPs, typical haloperidol and atypical risperidone, on attention and verbal memory functions in chronic schizophrenic patients, relative to the performance of a healthy control group. Further objectives were to determine the extent to which aspects of the clinical status of patients (psychiatric symptoms, parkinsonian extrapyramidal symptoms, anticholinergic medication) are associated with differences in neurocognitive performance.

\section{MATERIALS AND METHODS}

\section{Participants}

Twenty-eight outpatients with a diagnosis of SC were recruited for this study. The diagnosis of SC was made in accordance with the DSM-III-R criteria, for all patients and by the same psychiatrist. A total of 14 patients (11 men, 3 women) were selected at random to switch from a stable treatment with haloperidol to risperidone over a month, while 14 patients ( 11 men, 3 women) were selected at random to maintain haloperidol at their previous dosages. The mean age of the participants, age at diagnosis, duration of psychiatric illness or treatment, and level of education were not statistically different between the two patient groups (all $p$ 's $>.05$ ). A group of 18 healthy volunteers, with no history of psychiatric or neurological disorders and not currently taking psychoactive medication, was included in the study. This control group was matched with the two patient groups for age and education. None of the participants in the study had a history of drug or alcohol abuse or neurological disease and none required hospitalization for the duration of the study. Table 1 shows the demographic and clinical characteristics of each group. Written informed consent was obtained from each participant. The study was carried out according to the principles laid down in the Helsinki declaration, and it was approved by the Centre de recherche Université Laval-Robert-Giffard ethics committee.

\section{Tests and procedure}

The study design included four assessment periods: at baseline, 3, 6, and 12 months. The first assessment was conducted at baseline, when all the $28 \mathrm{SC}$ participants were on 
Table 1. Demographic and clinical characteristics of participants

\begin{tabular}{|c|c|c|c|c|}
\hline & $\begin{array}{c}\text { Risperidone } \\
n=14\end{array}$ & $\begin{array}{l}\text { Haloperidol } \\
\quad n=14\end{array}$ & $\begin{array}{l}\text { Control } \\
n=18\end{array}$ & $\begin{array}{l}\text { Statistical results } \\
\quad(p \text { value })\end{array}$ \\
\hline Sex (men: women) & $11: 3$ & $11: 3$ & $11: 7$ & \\
\hline Mean age, yr $(S D)$ & $40.6(9.9)$ & $44.1(9.4)$ & $41.2(9.5)$ & $>.05$ \\
\hline Mean education, $\operatorname{yr}(S D)$ & $11.6(3.8)$ & $12.3(2)$ & $13.4(2.6)$ & $>.05$ \\
\hline Mean age at diagnosis, $\mathrm{yr}(S D)$ & $26.3(6.2)$ & $28.4(9.8)$ & & $>.05$ \\
\hline Mean duration of continuous NLP treatment, yr $(S D)$ & $14.4(10.6)$ & $15.6(10.2)$ & & $>.05$ \\
\hline Mean dosage, $\mathrm{mg} /$ day $(S D)$ & $4 \quad(1.41)$ & $13 \quad(10.03)$ & & \\
\hline Range of NLP doses & $2-6 \mathrm{mg} /$ day & $2-40 \mathrm{mg} /$ day & & \\
\hline PANSS Positive $(S D)$ & $12.5(4.2)$ & $16 \quad(4.9)$ & & $<.05^{*}$ \\
\hline PANSS Negative $(S D)$ & $20.9(4.9)$ & $25.5(6.01)$ & & $<.05^{*}$ \\
\hline ESRS Parkinson $(S D)$ & $15 \quad(8.6)$ & $12.9(9.5)$ & & $>.05$ \\
\hline Participants treated with anticholinergic medication, $(n / 14)$ & 3 & 9 & & \\
\hline Mean dosage, $\mathrm{mg} /$ day $(S D)$ & $2.67(1.15)$ & $4.11(2.47)$ & & $<.05 *$ \\
\hline Range of dosage & $2-4 \mathrm{mg} /$ day & $1-8 \mathrm{mg} /$ day & & \\
\hline
\end{tabular}

Note. NLP $=$ neuroleptic; PANSS $=$ Positive and Negative Syndrome Scale; ESRS $=$ Extrapyramidal Symptom Rating Scale. $* p<.05$.

a stable regimen of haloperidol. After the first assessment, they were then randomly assigned either to the same drug regimen or to a switching crossover design involving substitution of haloperidol by risperidone. In the switching group, the baseline dose of the conventional drug decreased by $25 \%$ each week until the dose reached $0 \mathrm{mg}$, while there was a weekly progressive titration of risperidone of $0.5 \mathrm{mg}$ BID, $1 \mathrm{mg}$ BID, $1.5 \mathrm{mg}$ BID, and $2 \mathrm{mg}$ BID with a further adjustment of $0.5 \mathrm{mg}$ once or twice a day if judged clinically advantageous. Most of the participants reached the final dosage at 4 weeks, and all were stabilized within 8 weeks. A steady state of neuroleptization was maintained over 1 year and lorazepam was allowed on an as-needed basis except during the week before each test. During the course of the study, patients were administered anticholinergic medication (Procyclidine or Benztropine) as needed. The same psychiatrist consultant administered all the patients' medications.

At each assessment session, all participants were administered an adaptation of the CVLT (Delis et al., 1987) in Canadian French (Nolin, 1999) and the d2 Cancellation Test of attention (Brickenkamp \& Zillmer, 1998). The French version of the CVLT was administered in two different forms to avoid practice effects, and the order of administration of these forms was permuted across assessment periods (Form 1 at 0 month, Form 2 at 3 months, then Form 1 again at 6 months, and Form 2 at 12 months). These two forms of the CVLT have been validated in Canadian French (Nolin, 1999), and, as with the original English version, the test consists of two shopping lists of 16 items (with 4 items from each of 4 categories). The CVLT is a test of verbal memory and learning, which provides information on immediate recall, delayed recall, and learning strategies such as semantic organizational strategy. The following CVLT variables were selected for analysis: total recall (the sum of trials 1 to 5), semantic cluster ratio score, short-delay free recall (immediately after the interference task), and long-delay free recall (approximately 20-30 min after initial learning). The d2 Cancellation Test requires participants to cross out the letter $d$ surrounded by two dashes while ignoring distractor letters and dashes. This test measures selective and sustained visual attention, psychomotor processing speed, and response inhibition. The mean number of errors and the mean value of response times were used as scores.

Changes in symptom severity were assessed using the Positive and Negative Syndrome Scale (PANSS; Kay et al., 1989), a 30-item test. The score for each item ranges from 1 (no evidence) to 7 (extreme). The Extrapyramidal Symptom Rating Scale (ESRS; Chouinard et al., 1980) was used to assess the severity of extrapyramidal symptoms (EPS). Parkinsonian symptoms can impact on the performance of cognitive tasks with a psychomotor component. The score for parkinsonian symptom ratings was, therefore, used for subsequent analyses. For the duration of the study, the experimenter was blind to the participants' medication and psychopathological status, while the clinician assessing psychopathology and EPS was blind to their cognitive performance and medication status.

\section{Data Analyses}

An alpha level of .05 was used for all statistical tests. The changes in cognitive performance measures (verbal memory and attention) after treatment with typical or atypical NLPs were analyzed using repeated-measures analyses of variance (ANOVAs), performed separately for each variable, with Group (risperidone, haloperidol, control) as the between-subjects factor and Time (baseline, 3, 6, 12 months) as the within-subjects factor. Analyses were conducted to determine whether SC participants receiving risperidone or haloperidol differed from healthy controls on each of the CVLT and d2 measures over the 12-month follow-up. ANO- 
VAs were performed on transformed $(\log 10)$ data for semantic clusters and number of errors. To examine the differential effects of haloperidol and risperidone treatment on positive and negative symptoms in SC, ANOVAs with Group (risperidone, haloperidol) and Time, with repeated measures on the second factor, were performed on the PANSS positive and negative scores. When the sphericity assumption was violated, the Greenhouse-Geisser correction was used accordingly.

Additionally, post hoc within-subjects contrasts were performed on every significant main effect of Time to determine when an improvement occurred over the duration of the study (baseline, 3, 6, 12 months). Moreover, post hoc between-subjects effects were also conducted each time a main effect of Group was observed to determine which group differed from the other (SC vs. control; risperidone vs. haloperidol). To investigate the possibility that improved cognitive function might be associated with clinical symptoms (PANSS, ESRS) or concomitant medication (anticholinergic drugs), post hoc analyses were performed computing Pearson correlation coefficients. The Statistical Package for Social Sciences 11 (SPSS) software was used for all statistical analyses.

\section{RESULTS}

\section{Cognitive and Clinical Changes}

There were significant main effects of Group for CVLT recall trials 1 to $5[F(2,43)=18.63 ; p<.0001$, EtaSquared $\left.\left(\eta^{2}\right)=.46\right]$, semantic clustering $[F(2,43)=6.53$; $\left.p<.003 ; \eta^{2}=.23\right]$, short-delay free recall $[F(2,43)=$ 15,$\left.41 ; p<.0001 ; \eta^{2}=.42\right]$, and long-delay free recall $\left[F(2,43)=14.43 ; p<.0001 ; \eta^{2}=.40\right]$. Main effects of Time were also observed for CVLT recall trials 1 to 5 $\left[F(3,129)=12.73 ; p<.0001 ; \eta^{2}=.23\right]$, semantic clustering $\left[F(3,129)=4.5 ; p<.008 ; \eta^{2}=.10\right]$, short-delay free recall $\left[F(3,129)=13.51 ; p<.0001 ; \eta^{2}=.24\right]$, and longdelay free recall $\left[F(3,129)=6.94 ; p<.0001 ; \eta^{2}=.14\right]$. There was a significant Group by Time interaction for CVLT long-delay free recall $\left[F(6,129)=2.40 ; p=.03 ; \eta^{2}=.10\right]$ only. Nonsignificant Group by Time effects were observed for recall trials 1 to $5\left[F(6,129)=1.74 ; p=.141 ; \eta^{2}=\right.$ $.08]$, semantic clustering $\left[F(6,129)=.536 ; p=.747 ; \eta^{2}=\right.$ $.02]$, and short-delay free recall $[F(6,129)=1.73 ; p=$ $\left..119 ; \eta^{2}=.08\right]$.

Post hoc analyses were performed to determine which group, if any, differed from the others (SC vs. control; risperidone $v s$. haloperidol) in terms of CVLT performance. The results revealed that control participants performed better than both SC groups on recall trials 1 to $5[F(2,43)=$ $\left.37.21 ; p<.0001 ; \eta^{2}=.46\right]$, semantic clustering $[F(2,43)=$ $\left.13.03 ; p=.001 ; \eta^{2}=.23\right]$, short-delay free recall $[F(2,43)=$ $\left.30.74 ; p<.0001 ; \eta^{2}=.42\right]$, and in long-delay free recall $\left[F(2,43)=28.86 ; p<.0001 ; \eta^{2}=.40\right]$. There was no significant difference between the two groups of SC par- ticipants on all the CVLT measures $\{$ trials 1 to $5[F(2,43)=$ $\left..006 ; p=.935 ; \eta^{2}=.00\right]$; semantic clustering $[F(2,43)=$ $\left..04 ; p=.859 ; \eta^{2}=.00\right]$; short-delay recall $[F(2,43)=.04$; $\left.p=.833 ; \eta^{2}=.00\right]$; long-delay recall $[F(2,43)=.02 ; p=$ $\left.\left..896 ; \eta^{2}=.00\right]\right\}$. Post hoc analyses were also performed to determine whether the main effects of Time were associated with a practice effect over the repeated assessments of the CVLT. The results revealed significant linear contrasts in three CVLT variables (recall trials 1 to 5 , semantic clustering, short-delay free recall), suggesting a practice effect of the neurocognitive test for all participants over the assessment periods.

Further post hoc analyses on verbal long-delay free recall revealed an improvement over time under atypical risperidone treatment. Risperidone was effective at the 3-month $\left[F(1,13)=5.72 ; p=.033 ; \eta^{2}=.31\right]$ and 6-month assessments $\left[F(1,13)=7.36 ; p=.018 ; \eta^{2}=.36\right]$; performance remained stable thereafter until the 12-month assessment period $\left[F(1,13)=.20 ; p=.66 ; \eta^{2}=.02\right]$. Post hoc tests for the haloperidol group also revealed a significant enhancement in long-delay free recall at 3 months $[F(1,13)=6.91$; $\left.p=.02 ; \eta^{2}=.35\right]$. Improvement was also noted when participants were tested at 12 months $[F(1,13)=5.15 ; p=$ $\left..04 ; \eta^{2}=.28\right]$. Post hoc analyses for the control group revealed no significant difference in long-delay free recall performance from baseline to 12 months. These results suggest either that both NLP treatments had a direct effect in improving long-delay recall performance or that there was a practice effect not seen in the healthy controls because their performance plateaued over the 12-month follow-up study. The performance of each group on the CVLT subtests is presented in Figure 1.

ANOVAs on selective attention performance showed a main effect of Group for response time scores $[F(2,43)=$ $\left.8.41 ; p<.001 ; \eta^{2}=.28\right]$ only. There was no effect of Group for number of errors $\left[F(2,43)=.67 ; p=.517 ; \eta^{2}=\right.$ .03]. A main effect of Time was revealed for both measures of the $\mathrm{d} 2$ Cancellation Test, number of errors $[F(3,129)=$ $4.49 ; p<.008 ; \eta^{2}=.09$ ] and response time scores $\left[F(3,129)=13.88 ; p<.0001 ; \eta^{2}=.24\right]$. There was no interaction effect for both number of errors $[F(6,129)=$ $\left..91 ; p=48 ; \eta^{2}=.04\right]$ and response time $[F(6,129)=1.26$; $\left.p=.29 ; \eta^{2}=.06\right]$.

Post hoc analyses were performed to determine which group differed from the others on processing speed performance. The results showed that control participants performed better than both NLP treatment groups $[F(2,43)=$ $\left.15.72 ; p<.0001 ; \eta^{2}=.27\right]$. There was no significant difference between both haloperidol and risperidone groups in processing speed measures $\left[F(2,43)=2.1 ; p=.299 ; \eta^{2}=\right.$ .05]. Post hoc tests showed significant linear contrasts for response time variable. These results suggest a practice effect for all participants over the repeated administration of the $\mathrm{d} 2$ test. Further post hoc tests were conducted on the main effect of Time for number of errors. Results revealed significant linear contrasts, suggesting a practice effect for all participants over the repeated assessments study. The per- 

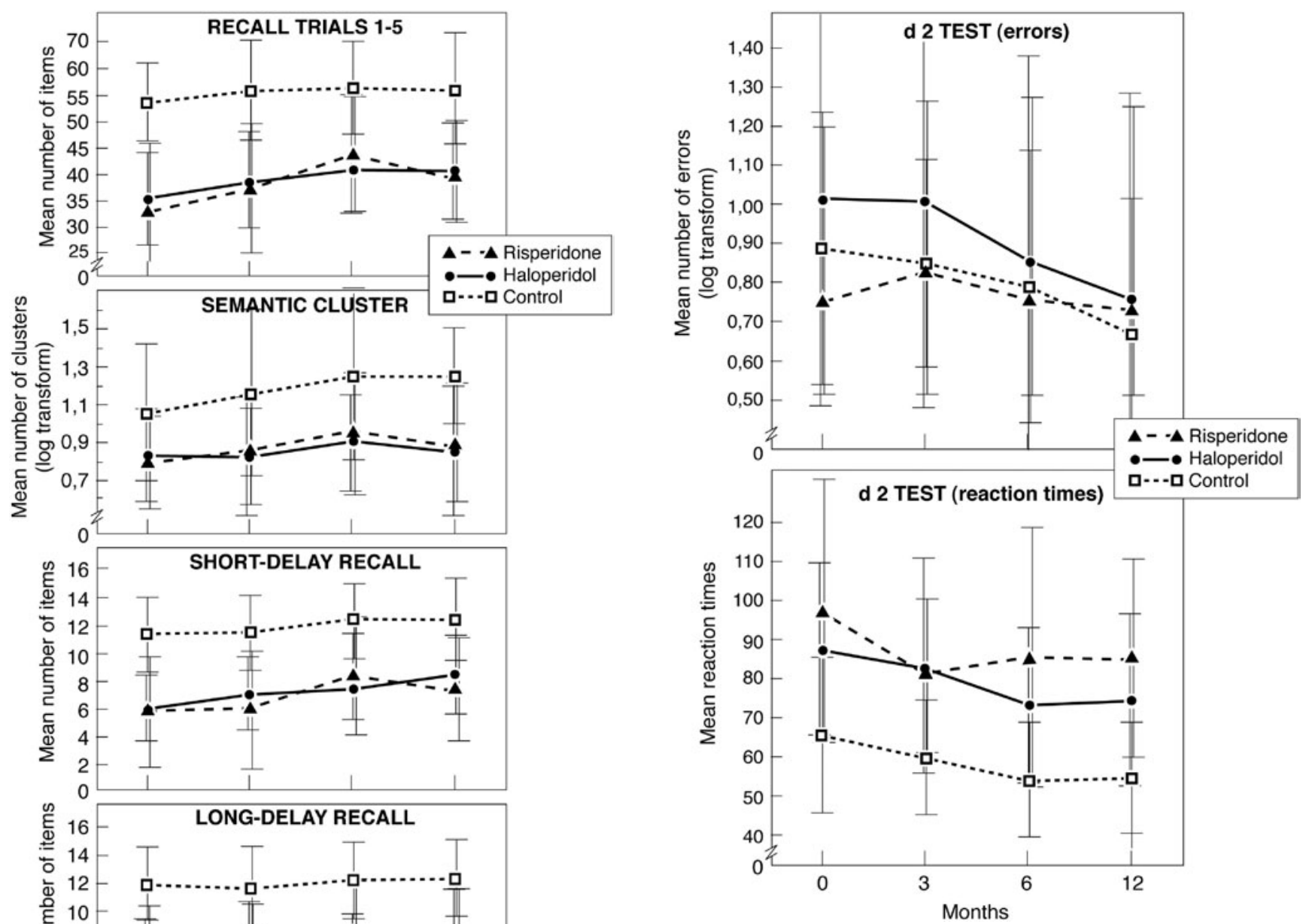

Fig. 2. Mean performance scores on d2 Cancellation Test over time for risperidone, haloperidol, and control participants.

$\left[F(1,13)=.67 ; p=.43 ; \eta^{2}=.05\right] ;$ level 3 vs. level 4 $\left.\left[F(1,13)=3.86 ; p=.07 ; \eta^{2}=.23\right]\right\}$, suggesting that the early efficacy of risperidone in reducing negative symptoms remained stable until the end of the study.

For the haloperidol group, post hoc analyses revealed no difference in the evolution of negative symptomatology from baseline to the end of the follow-up study \{level $1 \mathrm{vs}$. later $\left[F(1,13)=.49 ; p=.49 ; \eta^{2}=.04\right] ;$ level 2 vs. later $[F(1,13)=$ $\left..025 ; p=.88 ; \eta^{2}=.002\right]$; level 3 vs. level $4[F(1,13)=$ $\left.\left..408 ; p=.53 ; \eta^{2}=.03\right]\right\}$. Thus, there were no significant changes in symptomatology under typical NLP treatment. The course of the clinical symptomatology throughout the duration of the study, for both treatment groups, is presented in Figure 3. action for PANSS-negative symptoms $[F(3,78)=3.64 ; p=$ $\left..04 ; \eta^{2}=.12\right]$, indicating a differential effect of NLP class treatment on the evolution of symptomatology. Post hoc analyses for the risperidone group showed a significant difference between the results at baseline and after 3 to 12 months of treatment $\left[F(1,13)=6.12 ; p=.028 ; \eta^{2}=.32\right]$ for the PANSS-negative, showing that risperidone is effective in reducing negative symptoms after 3 months. Further analyses showed no difference between assessment at 3 months and the other assessment periods \{level $2 v s$. later

\section{Relationship Between Cognitive Function, Clinical Status, and Anticholinergic Medication}

Pearson correlations were conducted between CVLT scores, d2 scores, PANSS scores, ratings of parkinsonism, and anticholinergic medication. There was no steady relationship 


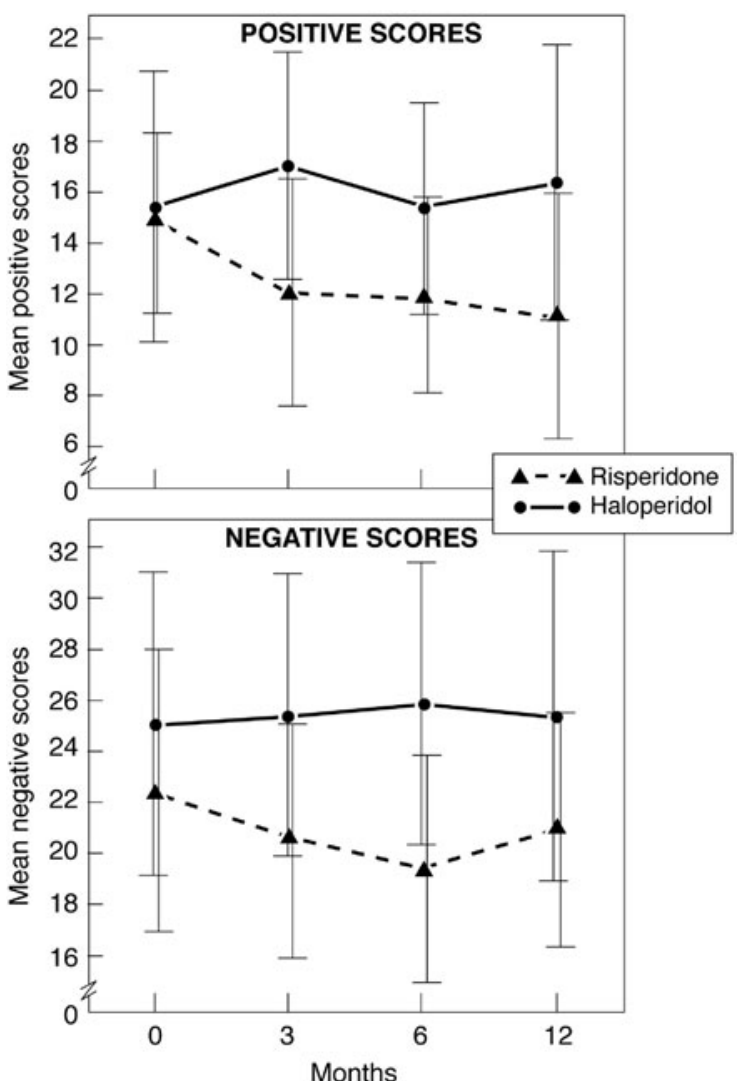

Fig. 3. Mean scores on Positive and Negative Syndrome Scale (PANSS) over time for risperidone and haloperidol treatment groups.

between cognitive performance and any of the clinical status and anticholinergic medication over all the 1-year follow-up study. All values of the Pearson correlation coefficients are presented in Table 2 .

\section{DISCUSSION}

The first objective of this study was to determine whether typical haloperidol and atypical risperidone treatments had a differential effect on SC subjects' verbal memory, attention, and symptomatology. The relationship between the severity of the symptomatology and anticholinergic drugs, parkinsonian symptoms, and cognitive functioning was also examined.

Our results revealed that SC patients showed significantly poorer performance on verbal memory tests and attentional processing speed than healthy controls. In addition, risperidone and haloperidol treatments did not have a differential effect on verbal memory and processing speed throughout the study. With the exception of long-delay recall, the SC patients' cognitive performance remained essentially unchanged at all assessment periods relative to that of the healthy controls. Our observations also showed a significant reduction in negative symptoms under risperidone treatment, but not with haloperidol. It appears that the evolution of symptoms, verbal memory performance, and processing speed performance all follow independent courses. Finally, anticholinergic drugs and parkinsonian EPS were not associated with memory or attention performance in these groups of SC patients.

Relative to healthy controls, participants with SC showed markedly impaired performance on the CVLT over the 12 months of the study. Our observations are in agreement with several studies reporting verbal learning and memory deficits in SC (Aleman et al., 1999; Hill et al., 2004; Paulsen et al., 1995). Most of these studies found that the verbal memory impairment seen in SC resulted from an encoding deficit, probably caused by the use of ineffective learning strategies. In our study, we observed that patients with SC recalled fewer items on the CVLT and used reduced semantic clustering strategies to hold information in memory. To

Table 2. Correlation values between cognitive performance (CVLT and $\mathrm{d} 2$ test), clinical symptoms (PANSS, ESRS), and concomitant medication (anticholinergic drug) over time

\begin{tabular}{|c|c|c|c|c|c|c|c|c|c|c|c|c|}
\hline & \multicolumn{4}{|c|}{ CVLT (sum of trials 1 to 5 ) } & \multicolumn{4}{|c|}{ CVLT (short-delay recall) } & \multicolumn{4}{|c|}{ CVLT (long-delay recall) } \\
\hline & $\mathrm{T} 1$ & $\mathrm{~T} 2$ & $\mathrm{~T} 3$ & $\mathrm{~T} 4$ & $\mathrm{~T} 1$ & $\mathrm{~T} 2$ & $\mathrm{~T} 3$ & $\mathrm{~T} 4$ & $\mathrm{~T} 1$ & $\mathrm{~T} 2$ & $\mathrm{~T} 3$ & $\mathrm{~T} 4$ \\
\hline PANSS positive & -.03 & -.08 & -.07 & -.12 & .09 & .19 & -.13 & -.16 & .06 & .03 & -.27 & -.11 \\
\hline PANSS negative & -.24 & -.17 & -.10 & -.01 & -.36 & -.26 & -.26 & -.07 & -.34 & -.07 & $-.42 *$ & -.06 \\
\hline ESRS Parkinson & -.04 & -.02 & -.01 & -.09 & -.10 & -.04 & -.07 & -.16 & -.11 & .10 & -.17 & -.11 \\
\hline \multirow[t]{3}{*}{ Anticholinergic medication } & -.08 & -.001 & -.22 & -.13 & -.12 & .25 & -.13 & -.23 & -.06 & .15 & -.17 & -.26 \\
\hline & \multicolumn{6}{|c|}{ D2 test (errors) } & & \multicolumn{5}{|c|}{ D2 test (response times) } \\
\hline & \multicolumn{2}{|c|}{$\mathrm{T} 1$} & \multicolumn{2}{|l|}{$\mathrm{T} 2$} & $\mathrm{~T} 3$ & \multicolumn{2}{|l|}{$\mathrm{T} 4$} & $\mathrm{~T} 1$ & \multicolumn{2}{|l|}{$\mathrm{T} 2$} & $\mathrm{~T} 3$ & $\mathrm{~T} 4$ \\
\hline PANSS positive & \multicolumn{2}{|c|}{$.50 *$} & \multicolumn{2}{|l|}{-.02} & .19 & \multicolumn{2}{|l|}{.21} & -.10 & \multicolumn{2}{|l|}{.32} & .02 & .06 \\
\hline PANSS negative & \multicolumn{2}{|c|}{-.08} & \multicolumn{2}{|l|}{.02} & -.19 & \multicolumn{2}{|l|}{-.37} & .21 & \multicolumn{2}{|l|}{.25} & -.05 & .24 \\
\hline ESRS Parkinson & \multicolumn{2}{|c|}{-.06} & \multicolumn{2}{|l|}{.15} & -.06 & \multicolumn{2}{|l|}{-.04} & $.38 *$ & \multicolumn{2}{|l|}{.10} & .19 & .15 \\
\hline Anticholinergic medication & \multicolumn{2}{|c|}{-.09} & \multicolumn{2}{|l|}{-.004} & .20 & \multicolumn{2}{|l|}{-.07} & -.15 & \multicolumn{2}{|l|}{.06} & .12 & .10 \\
\hline
\end{tabular}

Note. $\mathrm{T} 1=$ baseline, $\mathrm{T} 2=3$ months, $\mathrm{T} 3=6$ months, $\mathrm{T} 4=12$ months. PANSS $=$ Positive and Negative Syndrome Scale; ESRS $=$ Extrapyramidal Symptom Rating Scale; CVLT $=$ California Verbal Learning Test; 
some extent, our participants' use of poor semantic clustering may explain their inability to recall new information, such as a list of words, in an organized manner. It is noteworthy that impaired categorization and poor semantic clustering have also been observed in Parkinson's disease; parkinsonian patients were tested on the CVLT in two pharmacological conditions: the ON treatment (on levodopa therapy) and the practically OFF treatment (no levodopa intake after an overnight without treatment). Poor semantic clustering was observed only in the OFF condition (Pourcher et al., 2000). Thus, encoding strategies may partly depend on an optimal prefrontal dopaminergic input.

Interestingly, verbal long-delay free recall was somewhat improved under both risperidone and haloperidol treatment-but the SC patients remained impaired relative to the control group. The improvement observed under risperidone treatment is consistent with some prior reports (Bilder et al., 2002; Harvey et al., 2003; Kern et al., 1999). However, the improvement with haloperidol is somewhat unexpected, as the majority of those studies had reported no cognitive enhancement with conventional treatment. In some of those studies, the duration of the treatment assessment was as short as 6 to 8 weeks (Harvey et al., 2003; Kern et al., 1999). In addition, the inclusion of healthy controls may account for the divergence between our findings and those of some previous studies. Our observations do, however, agree with a 1-year study conducted by Lee et al. (1999), who found some improvement in delayed recall memory with typical NLPs, as measured by the Verbal List Learning Test (Buschke \& Fuld, 1974). Nevertheless, even though different CVLT versions were used alternately to avoid a practice effect, our findings must be interpreted with caution. Since the control group's performance plateaued, the improvement under both NLP treatments may simply represent a practice effect due to the repeated administration of the CVLT. Treatment with risperidone or haloperidol failed to improve any of the other CVLT measures. These results are consistent with other studies showing similar observations (Cuesta et al., 2001; Green et al., 2002; Purdon et al., 2000; Stip \& Lussier, 1996) and with a previous study (Rémillard et al., 2005) that reported similar effects on executive function.

The verbal memory impairment observed here is not explained by the use of anticholinergic medications, as there was no significant relationship between the anticholinergic drug dosages and any of the CVLT measures over the 12-month assessment period. These findings are at odds with some previous research (Frith, 1984; Mori et al., 2002) reporting that anticholinergic drugs have a deleterious effect on verbal memory in SC. The cause of this divergence is not clear, but several reports have also documented an absence of anticholinergic effect on verbal memory performance in SC (e.g., Green et al., 2002). It is very probable that anticholinergics have a different impact, depending on the type, the dose, and the population of schizophrenic patients studied.
With respect to attentional function, it was revealed that patients with SC do not produce more errors than control subjects on the $\mathrm{d} 2$ Cancellation Test. However, they take much more time to complete the task. These findings corroborate earlier reports of processing speed deficits in SC (Hong et al., 2002; Lussier \& Stip, 2001). The processing speed deficit observed in this experiment, under both NLP medications, remained stable until the end of the 12-month follow-up.

Relative to healthy performance, neither NLP enhanced SC participants' processing speed on the $\mathrm{d} 2$ test. These results do not agree with previous studies reporting superior cognitive efficiency under risperidone treatment on some specific tests of attention (Harvey et al., 2000; Stip \& Lussier, 1996). In those studies, the populations of patients were different: the disease duration and/or NLP exposure was shorter. However, the inclusion of a healthy control group and the long-term assessment of cognitive function suggest that these effects must be carefully evaluated with reference to so-called normal behavior over a sufficiently long period of time.

A significant reduction in both positive and negative psychiatric symptomatology was observed after initiating risperidone treatment. This finding is consistent with most previous studies, which found that psychiatric symptomatology improves more with risperidone than with typical NLP treatments (Peuskens, 1995; Rabinowitz \& Davidson, 2001; Yen et al., 2004). Risperidone possesses serotonergic and dopaminergic antagonist properties that may make it more effective than typical NLPs in the treatment of SC symptoms (Carman et al., 1995).

The majority of the CVLT measures, as well as processing speed, did not differ significantly in the risperidone and haloperidol groups over the course of the study, despite reduction in symptom severity under risperidone treatment. Moreover, there was no association between symptoms and cognitive impairment in either group of SC participants. Our results parallel studies that recognize cognitive dysfunction as a primary deficit that is independent of psychiatric manifestations and may persist after their resolution (Epstein et al., 1996; Hughes et al., 2003; Liu et al., 2000).

The complexity of psychiatric manifestations and cognitive function in $\mathrm{SC}$ and the pharmacodynamic properties of NLP treatments may benefit from longer-term studies. The contribution of the present study was an attempt to clarify the long-term effects of typical haloperidol and atypical risperidone medication on certain aspects of cognitive function in chronically ill and chronically treated patients relative to the performance of a healthy comparison group. These results do not, however, preclude the possibility that different benefits might be observed in a population of patients who were chronically treated from the onset of their disease and from a younger age with atypical NLPs, which have less impact on prefrontal functions. Only new long-term studies with a new generation of patients may provide clearer answers. 


\section{ACKNOWLEDGMENTS}

We are indebted to the subjects who volunteered their time for the duration of the study. This study benefited from a grant from Janssen-Ortho Foundation (Ontario, Canada). There is no financial relationship between the authors and the sponsor of the study. None of the authors are under any contract or receiving any salary from the sponsor of the study. The information in this manuscript and the manuscript itself have never been published either electronically or in print.

\section{REFERENCES}

Aleman, A., Hijman, R., de Haan, E.H., \& Kahn, R.S. (1999). Memory impairment in schizophrenia: A meta-analysis. American Journal of Psychiatry, 156, 1358-1366.

Bilder, R.M., Goldman, R.S., Volavka, J., Czobor, P., Hoptman, M., Sheitman, B., Lindenmayer, J.-P., Citrome, L., McEvoy, J., Kunz, M., Chakos, M., Cooper, T.B., Horowitz, T.L., \& Lieberman, J.A. (2002). Neurocognitive effects of clozapine, olanzapine, risperidone, and haloperidol in patients with chronic schizophrenia or schizoaffective disorder. American Journal of Psychiatry, 159, 1018-1028.

Bozikas, V.P., Kosmidis, M.H., Kioperlidou, K., \& Karovatos, A. (2004). Relationship between psychopathology and cognitive functioning in schizophrenia. Comprehensive Psychiatry, 45, 392-400.

Brickenkamp, R. \& Zillmer, E. (1998). The D2 Test of Attention (1st US ed.). Seattle: Hogrefe \& Huber Publishers.

Buschke, H. \& Fuld, P.A. (1974). Evaluating storage, retention, and retrieval in disordered memory and learning. Neurology, 24, 1019-1025.

Carman, J., Peuskens, J., \& Vangeneugden, A. (1995). Risperidone in the treatment of negative symptoms of schizophrenia: A meta-analysis. International Clinical Psychopharmacology, 10, 207-213.

Chouinard, G., Ross-Chouinard, A., Annable, L., \& Jones, B.D. (1980). Extrapyramidal Symptom Rating Scale (ESRS). Canadian Journal of Neurological Sciences, 7, 233-243.

Cuesta, M.J., Peralta, V., \& Zarzuela, A. (2001). Effects of olanzapine and other antipsychotics on cognitive function in chronic schizophrenia: A longitudinal study. Schizophrenia Research, $48,17-28$.

Delis, D.C., Kramer, J.H., Kaplan, E., \& Ober, B.A. (1987). The California Verbal Learning Test-Research edition. New York: Psychological Corporation.

Epstein, J.I., Keefe, R.S., Roitman, S.L., Harvey, P.D., \& Mohs, R.C. (1996). Impact of neuroleptic medications on continuous performance test measures in schizophrenia. Biological Psychiatry, 39, 902-905.

Fletcher, P.C., Shallice, T., \& Dolan, R.J. (1998). The functional roles of prefrontal cortex in episodic memory. I. Encoding. Brain, 121, 1239-1248.

Frith, C.D. (1984). Schizophrenia, memory, and anticholinergic drugs. Journal of Abnormal Psychology, 93, 339-341.

Fukuzako, H., Kodama, S., Fukuzako, T., Yamada, K., Hokazono, Y., Ueyama, K., Hashiguchi, T., Takenouchi, K., Takigawa, M., \& Takeuchi, K. (1995). Shortening of the hippocampal formation in first-episode schizophrenic patients. Psychiatry and Clinical Neurosciences, 49, 157-161.

Green, M.F. (1996). What are the functional consequences of neuro- cognitive deficits in schizophrenia? American Journal of Psychiatry, 153, 321-330.

Green, M.F., Marder, S.R., Glynn, S.M., McGurk, S.R., Wirshing, W.C., Wirshing, D.A., Liberman, R.P., \& Mintz, J. (2002). The neurocognitive effects of low-dose haloperidol: A twoyear comparison with risperidone. Biological Psychiatry, 51, 972-978.

Harvey, P.D., Green, M.F., McGurk, S.R., \& Meltzer, H.Y. (2003). Changes in cognitive functioning with risperidone and olanzapine treatment: A large-scale, double-blind, randomized study. Psychopharmacology, 169, 404-411.

Harvey, P.D., Moriarty, P.J., Serper, M.R., Schnur, E., \& Lieber, D. (2000). Practice-related improvement in information processing with novel antipsychotic treatment. Schizophrenia Research, 46, 139-148.

Heckers, S., Rauch, S.L., Goff, D., Savage, C.R., Schacter, D.L., Fischman, A.L., \& Alpert, N.M. (1998). Impaired recruitment of the hippocampus during conscious recollection in schizophrenia. Nature Neuroscience, 1, 318-323.

Hill, S.K., Beers, S.R., Kmiec, J.A., Keshavan, M.S., \& Sweeney, J.A. (2004). Impairment of verbal memory and learning in antipsychotic-naive patients with first-episode schizophrenia. Schizophrenia Research, 68, 127-136.

Holthausen, E.A., Wiersma, D., Sitskoorn, M.M., Dingemans, P.M., Schene, A.H., \& van den Bosch, R.J. (2003). Long-term memory deficits in schizophrenia: Primary or secondary dysfunction? Neuropsychology, 17, 539-547.

Hong, K.S., Kim, J.G., Koh, H.J., Koo, M.S., Kim, J.H., Lee, D., \& Kim, E. (2002). Effects of risperidone on information processing and attention in first-episode schizophrenia. Schizophrenia Research, 53, 7-16.

Hughes, C., Kumari, V., Soni, W., Das, M., Binneman, B., Drozd, S., O’Neil, S., Mathew, V., \& Sharma, T. (2003). Longitudinal study of symptoms and cognitive function in chronic schizophrenia. Schizophrenia Research, 59, 137-146.

Johnson, S.C., Saykin, A.J., Flashman, L.A., McAllister, T.W., \& Sparling, M.B. (2001). Brain activation on fMRI and verbal memory ability: Functional neuroanatomic correlates of CVLT performances. Journal of the International Neuropsychological Society, 7, 55-62.

Kay, S.R., Opler, L.A., \& Lindenmayer, J.P. (1989). The Positive and Negative Syndrome Scale (PANSS): Rationale and standardization. British Journal of Psychiatry, 155, 59-67.

Kern, R.S., Green, M.F., Marshall, B.D., Jr., Wirshing, W.C., Wirshing, D., McGurk, S.R., Marder, S.R., \& Mintz, J. (1999). Risperidone versus haloperidol on secondary memory: Can newer medications aid learning? Schizophrenia Bulletin, 25, 223-232.

Lee, M.A., Jayathilake, K., \& Meltzer, H.Y. (1999). A comparison of the effect of clozapine with typical neuroleptics on cognitive function in neuroleptic-responsive schizophrenia. Schizophrenia Research, 37, 1-11.

Liu, S.K., Chen, W.J., Chang, C.-J., \& Lin, H.-N. (2000). Effects of atypical neuroleptics on sustained attention deficits in schizophrenia: A trial of risperidone versus haloperidol. Neuropsychopharmacology, 22, 311-319.

Lussier, I. \& Stip, E. (2001). Memory and attention deficits in drug naive patients with schizophrenia. Schizophrenia Research, 48, 45-55.

Meltzer, H.Y. \& McGurk, S.R. (1999). The effects of clozapine, risperidone, and olanzapine on cognitive function in schizophrenia. Schizophrenia Bulletin, 25, 233-255. 
Mori, K., Yamashita, H., Nagao, M., Horiguchi, J., \& Yamawaki, S. (2002). Effects of anticholinergic drug withdrawal on memory, regional cerebral blood flow and extrapyramidal side effects in schizophrenic patients. Pharmacopsychiatry, 35, 6-11.

Nolin, P. (1999). Analyses psychométriques de l'adaptation Française du California Verbal Learning Test (CVLT) (Psychometric validation of French version of the CVLT). Revue Québécoise de Psychologie, 20, 39-55.

Nuechterlein, K.H. \& Dawson, M.E. (1984). Information processing and attentional functioning in the developmental course of schizophrenic disorders. Schizophrenia Bulletin, 10, 160-203.

Paulsen, J.S., Heaton, R.K., Sadek, J.R., Perry, W., Delis, D.C., Braff, D., Kuck, J., Zisook, S., \& Jeste, D.V. (1995). The nature of learning and memory impairments in schizophrenia. Journal of the International Neuropsychological Society, 1, 88-99.

Peuskens, J. (1995). Risperidone in the treatment of patients with chronic schizophrenia: A multi-national, multi-centre, doubleblind, parallel-group study versus haloperidol. Risperidone Study Group. British Journal of Psychiatry, 166, 712-726.

Pourcher, E., Thériault, M., \& Lussier, J. (2000). Verbal retrieval in idiopathic Parkinson's disease: An "on-off" study. Movement Disorders, 15(Suppl. 3), 188.

Purdon, S.E., Jones, B.D.W., Stip, E., Labelle, A., Addington, D., David, S.R., Breier, A., \& Tollefson, G.D. (2000). Neuropsychological change in early phase schizophrenia during 12 months of treatment with olanzapine, risperidone, or haloperidol. Archives of General Psychiatry, 57, 249-258.

Rabinowitz, J. \& Davidson, M. (2001). Risperidone versus haloperidol in long-term hospitalized chronic patients in a double blind randomized trial: A post hoc analysis. Schizophrenia Research, 50, 89-93.

Rémillard, S., Pourcher, E., \& Cohen, H. (2005). The effect of neuroleptic treatments on executive function and symptomatol- ogy in schizophrenia: A 1-year follow up study. Schizophrenia Research, 80, 99-106.

Shallice, T., Fletcher, P., Frith, C.D., Grasby, P., Frackowiak, R.S., \& Doland, R.J. (1994). Brain regions associated with acquisition and retrieval of verbal episodic memory. Nature, 14, 633-635.

Stip, E. \& Lussier, I. (1996). The effect of risperidone on cognition in patients with schizophrenia. Canadian Journal of Psychiatry, 41(Suppl. 2), 35S-40S.

Strauss, M.E., Reynolds, K.S., Jayaram, G., \& Tune, L.E. (1990). Effects of anticholinergic medication on memory in schizophrenia. Schizophrenia Research, 3, 127-129.

Toichi, M., Findling, R.L., Kubota, Y., Calabrese, J.R., Wiznitzer, M., McNamara, N.K., \& Yamamoto, K. (2004). Hemodynamic differences in the activation of the prefrontal cortex: Attention vs. higher cognitive processing. Neuropsychologia, 42, 698-706.

Tulving, E., Kapur, S., Craik, F.I., Moscovitch, M., \& Houle, S. (1994). Hemispheric encoding/retrieval asymmetry in episodic memory: Positron emission tomography findings. Proceedings of the National Academy of Sciences of the United States of America, 91, 2016-2020.

Vendrell, P., Junque, C., Pujol, J., Jurado, M.A., Molet, J., \& Grafman, J. (1995). The role of prefrontal regions in the Stroop task. Neuropsychologia, 33, 341-352.

Weiss, A.P., Zalesak, M., DeWitt, I., Goff, D., Kunkel, L., \& Heckers, S. (2004). Impaired hippocampal function during the detection of novel words in schizophrenia. Biological Psychiatry, $55,668-675$.

Yen, Y.-C., Lung, F.-W., \& Chong, M.-Y. (2004). Adverse effects of risperidone and haloperidol treatment in schizophrenia. Progress in Neuro-Psychopharmacology \& Biological Psychiatry, 28, 285-290. 